modulators of $\mathbf{P}$ glycoprotein must include pharmacokinetic studies since interactions can occur with cytotoxic drugsfor example, etoposide's activity is increased by $80 \%$ when it is given in combination with cyclosporin A. ${ }^{21}$ These trials should focus on those cancers that are known to express high concentrations of $\mathrm{P}$ glycoprotein (including renal and colorectal cancers and sarcomas). Since $P$ glycoprotein is expressed in normal tissues there is some concern that its modulators might alter the cellular transport of physiological metabolites such as bilirubin and thereby delay the clearance of cytotoxic drugs that undergo hepatobiliary excretion. These clinical trials should therefore be performed in units used to handling the toxicity associated with intensive chemotherapy.

DAVID R FERRY

Senior registrar in medical oncology

DAVID J KERR

Professor of clinical oncology

CRC Department of Clinical Oncology,

Clinical Research Block,

Queen Elizabeth Hospital,

Birmingham B15 2TH

1 Bielder $\mathrm{J}$, Reiehm $\mathrm{H}$. Cellular resistance to Chinese hamster cells in vitro: cross resistance, radioautographic studies and cytogenetic studies. Cancer Res 1970;30:1174-84.

2 Riordan JR, Ling V. Purification of P-glycoprotein from plasma membranes vesicles of Chinese hamster ovary cell mutants with reduced colchine permeability. $¥$ Biol Chem 1979;254:12701-5.

Carlsen SA, Till JE, Ling V. Modulation of membrane drug permeability in Chinese hamster ovary cells. Biochem Biophy Acta 1979;455:900-12.

4 Gros P, Croop J, Housman D. Mammalian multidrug resistance gene: complete cDNA sequence indicates a strong hormology to bacterial transport proteins. Cell 1986;46:371-80.
5 Raviv Y, Pollard HB, Bruggemann EP, Pastan I, Gottesman MM. Photosensitised labelling of a functional multidrug transporter in living drug resistant tumour cells. $f$ Biol Chem 1990;265: 3975-80.

Higgins CF, Gottesman MM. Is the multidrug resistance transporter a flippase? Trends Biochem Sci 1992;17:18-21.

7 Ferry DR, Russell M, Cullen MH. P-glycoprotein possesses a 1,4-dihydropyridine-selective drug acceptor site which is allosterically couple to a vinca-alkaloid-selective binding site. Biochem Biophys Res Commun 1992;188:440-5.

8 Gottesman MM, Pastan I. Biochemistry of multidrug resistance mediated by the multidrug transporter. Annu Rev Biochem 1993;62:385-427.

9 Cole SPC, Bhardwaj G, Gerlach JH, Mackie JE, Grant CE, Almquist AJ, et al. Overexpression of a transporter in a multidrug-resistant human lung cancer cell line. Science 1992;258:1650-4.

10 Fojo AT, Ueda K, Salmon DJ, Poplack DG, Gottesman MM, Pastan I. Expression of a multidrug resistance gene in human tumors and tissues. Proc Natl Acad Sci USA 1989;84:265-9.

11 Cordon-Cardo C, O'Brien J, Casals C, Boccia J, Bertino JR. Immunoanatomical and immunopathological expression of the multidrug-resistance gene product. Cancer Cells 1989;7:87-93.

12 Kuwaturu Y, Yoshimura A, Hanade S, Utsunomiya A, Makino T, Ishibashi K, et al. Expression of the multidrug transporter, P-glycoprotein in acute leukaemia cells and correlation to clinical drug resistance. Cancer 1990;66:868-73.

13 Chan HLS, Thorner PS, Haddad G, Ling V. Immunohistochemical detection of P-glycoprotein prognostic correlation in soft tissue sarcoma of childhood. $f$ Clin Oncol 1990;8:689-704.

14 Chan HLS, Haddad G, Thorner PS, DeBoer G, Lin YP, Ondrusek N, et al. P-glycoprotein as a predictor of outcome of therapy for neuroblastoma. N Engl ₹ Med 1991;325:1608-14.

15 Tsuruo T, Iida H, Kitatani Y, Yokota K, Tsukagoshi S, Sakurai Y. Effects of quinidine and related compounds on cytotoxicity and cellular accumulation of vincristine and adriamycin in drug resistant tumour cells. Cancer Res 1984;44:4303-7.

16 Endicott JA, Ling V. The biochemistry of P-glycoprotein-mediated multidrug resistance. Annu Rev Biochem 1989;58:137-71.

17 Miller TP, Grogan TM, Dalton WS, Spier CM, Scheper RJ, Salmon SE. P-glycoprotein expression in malignant lymphoma and reversal of clinical drug resistance with chemotherapy plus high dose verapamil. C Clin Oncol 1991;9:17-24.

18 Sonneveld P, Durie BGM, Lokhorst HM, Marie J-P, Solbu G, Suciu S, et al. Modulation of multidrug resistant multiple myeloma by cyclosporin. Lancet 1992;340:255-9.

19 Wishart GC, Harnett C, Kerr DJ, Paul J, Machem MA, Soukup M, Leonard RCF, Kaye SB. A randomised placebo controlled trial of quinidine as a resistance modulator in patients with advanced breast cancer treated with epirubin [abstract]. Proceeding of American Society of Clinical Oncology 1993;12:33.

20 Mickisch GH, Merlino GT, Galski H, Gottesman MM. Transgenic mice that express the human multidrug-resistance gene in bone marrow enable a rapid identification of agents that reverse drug resistance. Proc Natl Acad Sci USA 1991;88:547-51.

21 Lum BL, Kanbish S, Yahanda AM, Adler KM, Jew L, Ehsan NM, et al. Alteration of etoposide pharmacokinetics and pharmacodynamics by cyclosponine in a phase I trial to modulate multidrug resistance. $f$ Clin Oncol 1992;10:1635-42.

\title{
Human parvovirus B19
}

\section{The cause of an illness with an erythematous rash and a possible problem in pregnancy}

Infection with parvovirus B19 is most common in children between the ages of 4 and 11. About half the infections are asymptomatic, and many of the remainder cause a nonspecific illness of the respiratory tract. ${ }^{1}$ The most common distinct disease associated with the infection is erythema infectiosum-also known as fifth disease or slapped cheek disease. ${ }^{2}$ Erythema infectiosum is usually diagnosed clinically only when there is an outbreak of illness with a rash in young children and red cheeks are a prominent feature. Illness with an erythematous rash due to parvovirus B19 infection is worldwide and common, but in the absence of laboratory tests it is often diagnosed as rubella (both rubella and parvovirus B19 infection have a similar seasonality), allergy, or simply a "viral infection."

An arthropathy similar to that seen in rubella may be associated with parvovirus B19 infection. The most common pattern is symmetric arthralgia or arthritis in the small joints of the hands, with the wrists, knees, and ankles affected in some cases. Joint symptoms occur in only $10 \%$ of children with the infection but in as many as $80 \%$ of adult women. The symptoms and signs of the joint disorder usually resolve within two weeks, but they may persist for months and occasionally for years. ${ }^{34}$

The diseases described above occur in normal people. In those with some underlying haemolytic state-such as sickle cell anaemia or hereditary spherocytosis-parvovirus B19 infection is associated with a transient acute worsening of the anaemia. This aplastic crisis results from a halt in erythropoiesis in the bone marrow for five to seven days - the patients have a normal immune system and clear the virus in the usual way. ${ }^{5}$ By contrast, parvovirus B19 infection in patients with some immunodeficiency states (Nezelof's syndrome, acute lymphatic leukaemia, and HIV infection) is usually chronic and associated with persistent or remitting and relapsing anaemia. ${ }^{67}$ The bone marrow is typical of that seen in aplastic crises complicating haemolytic anaemias; the underlying cause is the weak humoral immune response in these patients. Administration of human immunoglobulin will result in transient or permanent clearance of the virus and improvement of the anaemia.

Because of the similarity between the rashes in illnesses due to parvovirus B19 infection and rubella and the occurrence of fetal damage in parvovirus infections in animals, an adverse effect of parvovirus B19 infection might be expected in pregnancy. Early studies suggested that the spontaneous abortion rate was increased. There has been one systematic study in Britain of the outcome of pregnancies complicated by parvovirus B19 infection confirmed in a laboratory. ${ }^{8}$ This showed no increase in the number of spontaneous abortions in the first trimester, but 1 in 10 of the pregnancies ended in spontaneous abortion during the second trimester-10 times the expected rate. In the cases in which the mother had clear cut symptoms the pregnancy was lost on average four to six weeks after the onset of the maternal illness.

Many studies in Europe and the United States have shown that hydrops fetalis sometimes occurs as a consequence of infection with parvovirus B19 virus in the second or third trimester..$^{9}$ The hydrops may be transient or ultimately fatal and is consistently associated with anaemia and sometimes with myocarditis in the fetus. Whether intrauterine parvo- 
virus $\mathrm{B} 19$ infection might be an infrequent cause of anatomical or functional abnormalities remains unclear. Such abnormalities are not seen commonly when parvovirus B19 infection complicates pregnancies: most pregnancies continue to full term delivery of normal infants. There have been some unpublished observations indicating that parvovirus B19 infection of the fetus may result in congenital red cell aplasia or various disorders of the central nervous system. If certain abnormalities are, indeed, specifically linked to parvovirus B19 infection then the incidence is less than $1 \%$ of all pregnancies complicated by the infection-to prove this beyond all doubt would require a study of more than 9000 such pregnancies with long term follow up of the infants.

Diagnostic tests for parvovirus B19 infection are available in only a few laboratories. The use of commercial kits should be introduced with caution and with the advice of people with long experience of laboratory diagnosis of the infection. Clearly, laboratory diagnosis is worth while for patients with severe anaemia, in outbreaks of illness with an erythematous rash, for individual patients with a rash in pregnancy, and in cases of hydrops fetalis.

Severe anaemia in immunocompromised patients can be treated with intravenous human immunoglobulin. Hydrops fetalis associated with fetal anaemia caused by parvovirus B19 infection may have long term harmful consequences, but in the absence of convincing evidence of any congenital abnor- malities due to intrauterine infection there is no indication for therapeutic abortion in cases of B19 infection. Let us hope that by the end of the decade remaining questions about fetal parvovirus B19 infection will have been resolved and that a vaccine will be available for certain high risk groups such as patients with sickle cell disease.

J R PATTISON Professor

University College London,

Rayne Institute,

London WC1E 6J

1 Grilli EA, Anderson MJ, Hoskins TW. Concurrent outbreaks of influenza and parvovirus B19 in a boys' boarding school. Epidemiol Infect 1989;103:359-70.

2 Anderson MJ, Lewis E, Kidd IM, Hall SM, Cohen BJ. An outbreak of erythema infectiosum associated with human parvovirus infection. $\mathcal{F}$ Hyg 1984;92:85-93.

3 Reid DM, Reid TMS, Brown T, Rennie JAN, Eastmond CJ. Human parvovirus-associated arthritis: a clinical and laboratory description. Lancet 1985;ii:422.

4 White DG, Mortimer PP, Blake DR, Woolf AD, Cohen BJ, Bacon PA. Human parvovirus arthropathy. Lancet $1985 ; \mathrm{i}: 419$.

5 Serjeant GR, Topley JM, Mason K, Serjeant BE, Pattison JR, Jones SE, et al. Outbreak of aplastic crisis in sickle cell anaemia associated with parvovirus-like agent. Lancet 1981;ii:595-7.

6 Kurtzman GJ, Cohen B, Meyers P, Amunullah A, Young NS. Persistent B19 parvovirus infection as a cause of severe chronic anaemia in children with acute lymphocytic leukaemia. Lancet 1988;i:1159-62.

7 Kurtzman GJ, Ozawa K, Cohen B, Hanson G, Oseas R, Young NS. Chronic bone marrow failure due to persistent B19 parvovirus infection. N Engl Y Med 1987;317:287-94.

8 Public Health Laboratory Service Working Party on "Fifth" Disease. Prospective study of human parvovirus (B19) infection in pregnancy. BMF 1990;300:1166-70.

Carrington D, Whittle MJ, Gibson AAM, Brown T, Field AM, Gilmore DH, et al. Maternal serum $\alpha$-fetoprotein $-a$ marker of fetal aplastic crises during intrauterine human parvovirus infection. $\alpha$-fetoprotein-a marker

10 Porter HJ, Khong TY, Evans MF, Chan VTW, Fleming KA. Parvovirus as a cause of hydrops fetalis: detection by in situ DNA hybridisation. 7 Clin Pathol 1988;41:381-3.

\section{Chlamydia trachomatis and sexually transmitted disease}

\section{What do we know and what shall we do?}

Chlamydial organisms are small bacteria that need to be inside cells to multiply. There are three species, Chlamydia trachomatis, $C$ psittaci, and $C$ pneumoniae. Serotypes A, B, and C of $C$ trachomatis are the cause of the blinding disease trachoma. Serotypes D to $\mathrm{K}$ are sexually transmitted and, world wide, are an important cause of morbidity in both men and women. In men chlamydial infection causes up to half of all acute non-gonococcal urethritis and at least one third of acute epididymitis. ${ }^{1}$ In women such infection causes up to half of all mucopurulent or follicular cervicitis, and in developed countries up to $60 \%$ of pelvic inflammatory disease, ${ }^{1}$ a condition associated with a substantial risk of subsequent infertility and ectopic pregnancy. $C$ trachomatis infection may also trigger reactive arthritis in men and women. ${ }^{2}$ Transmission of the organisms to newborn infants from mothers, usually during birth, may lead to neonatal conjunctivitis and pneumonia.

Progress in understanding the pathogenesis of genital chlamydial infections has come with the recognition that some persistent or recurrent disease (including chronic nongonococcal urethritis and ectopic pregnancy and infertility associated with pelvic inflammatory disease) may be due to a delayed hypersensitivity response to $C$ trachomatis. ${ }^{3}$ So how widespread is this infection in Britain? Unfortunately, the information we have is based on a few prevalence studies in general practice and in gynaecology and antenatal clinics ${ }^{4-6}$; in these, $7-12 \%$ of women in the childbearing years have been found to be infected. The number of men attending genitourinary medicine clinics in England with a new attack of nonspecific genital infection (about half of which may be caused by $C$ trachomatis) showed a sustained rise throughout the late 1970 s and early 1980s, then declined slightly, and more recently stabilised. In 1991 there were about 72000 cases. $^{7}$ While gonococcal infections have continued to decline, chlamydial infections remain a blight. ${ }^{7}$

Why should this be? The answers seem fairly clear. Firstly, genital chlamydial infections-at least in women-are usually asymptomatic and thus easily become widespread. Secondly, strategies for detection and screening have been haphazard, so that the identification of infected people, with or without symptoms, has been incomplete. Thirdly, until recently the methods used for routine diagnosis were insensitive. ${ }^{8}$ Fourthly, contact tracing has taken a back seat since the emergence of HIV and AIDS. One consequence is a lot of individual anguish and big demands on health resources. My own conservative estimate is that genital and associated chlamydial infections and their sequelae cost Britain at least $£ 50 \mathrm{~m}$ a year for diagnosis and management. An even more depressing picture has been painted for the United States. ${ }^{9}$

Thinking positively, however, we should emphasise that chlamydial infections are treatable. In Sweden a programme of widespread screening was started in the early 1980s, and assiduous contact tracing and treatment have been effective in vastly reducing the incidence and prevalence of genital chlamydial infections in the population-to the point where in 1991 they were almost negligible. ${ }^{10} \mathrm{~A}$ small increase in infection in the 15-19 year age group in 1992 (T Ripa, personal communication) should dispel any complacency, however, and the results of subsequent monitoring will be awaited with considerable interest. The small size of the Swedish population and their attitudes to sexual health may well have made the problem easier to deal with, but there seems no inherent reason why similar results should not be achieved in Britain. 